\title{
Research on Optimal Control Strategy for Unpowered Downslope of High-Voltage Inspection Robot Based on Motor Temperature Rise in Complexity Microgrid Networks
}

\author{
Zhiyong Yang $\mathbb{D}^{1},{ }^{1}$ Qiao Fang, ${ }^{1}$ Zihao Zhang, ${ }^{1}$ Xing Liu, ${ }^{1}$ Xianjin Xu $\mathbb{D}^{1},{ }^{1}$ Yu Yan, ${ }^{2}$ \\ and Chen Miao' \\ ${ }^{1}$ College of Mechanical Engineering, Hubei University of Technology, Wuhan 430068, China \\ ${ }^{2}$ State Grid of Hunan Electric Power Company Maintenance Company, Changsha 410004, China \\ Correspondence should be addressed to Zhiyong Yang; yzy@hbut.edu.cn
}

Received 16 November 2020; Revised 13 January 2021; Accepted 27 April 2021; Published 12 May 2021

Academic Editor: Xin Li

Copyright ( 2021 Zhiyong Yang et al. This is an open access article distributed under the Creative Commons Attribution License, which permits unrestricted use, distribution, and reproduction in any medium, provided the original work is properly cited.

\begin{abstract}
In order to avoid the motor damage caused by excessive temperature rise of armature winding of the walking motor during braking of high-voltage inspection robot in complexity microgrid networks, an unpowered downhill speed and energy recovery optimization control strategy is proposed based on temperature rise characteristics of the walking motor. Firstly, the thermal equivalent circuit model of the walking motor is established, and the mapping relationship between the armature winding temperature of the walking motor and ambient temperature is solved; secondly, the influence of armature winding temperature on unpowered downhill speed and energy recovery control strategy of robot is analyzed; thirdly, according to the temperature of front and rear wheel walking motors and the temperature difference between them, the optimal control strategy of unpowered downhill speed and energy recovery of robot is put forward; fourthly, by adjusting the duty ratio $u$ of the energy consumption speed control system and the front wheel feedback brake distribution factor $\lambda$, the temperature difference between the front and rear wheel walking motors is reduced. Through the experimental analysis on the simulated line, it is verified that the unpowered downhill speed and energy recovery optimization control method based on the temperature rise characteristics of the walking motor can effectively reduce the temperature difference between the front and rear wheels.
\end{abstract}

\section{Introduction}

With the development of high-voltage inspection robot technology in complexity microgrid networks, most highvoltage transmission lines are typical catenary structures. The line between two adjacent towers is downhill first and then uphill. The downhill section provides conditions for the robot to realize unpowered downhill speed control and energy recovery. The robot performs inspection tasks along the transmission line. With the inspection tasks, the walking motor temperature gradually increases, especially in the unpowered downhill process. On the one hand, if the traveling motor generates serious heat and the heat cannot be dissipated in time, it will affect the working performance and service life of the motor, and in severe cases, it will damage the motor winding due to the burning of the insulating paint; on the other hand, the encoder is installed at the end of the traveling motor. According to the heat conduction characteristics, when the temperature of the traveling motor rises, it will inevitably cause the encoder temperature to rise, and the encoder will reach the highest working temperature before the traveling motor. When the encoder temperature exceeds the maximum allowable temperature for a certain period of time, it will cause irreparable damage to the encoder and make the speed and direction of the robot uncontrollable. In addition, it often happens that the inspection robot cannot finish the inspection task on time due to lack of power during the inspection. Therefore, the unpowered downhill speed and energy recovery optimization control strategy based on the 
temperature rise characteristics of the walking motor is particularly important and imminent.

In the past, many scholars had done extensive research on motor speed control and put forward many advanced control strategies. At present, motor speed control methods include PID, sliding mode, internal model, and adaptive, predictive, and active disturbance suppression control [1-8]. A predictive control strategy combining DC-DC converter with PMDC machine is proposed in [9]; it was proposed to quantitatively adjust the power consumption of the energy consumption resistor by adjusting the on-off duty ratio of the energy consumption circuit, so as to realize speed control in downhill process in [10]. A fuzzy logic controller was proposed to provide accurate steering angle and driving speed to control robot speed in [11]. An optimal control strategy based on active disturbance rejection control (ADRC) was proposed to achieve high-precision control of PMSM in [12]. Although these methods can control motor speed well, the temperature rise characteristics of the motor are not studied. Temperature rise characteristics of permanent magnet synchronous motor were analyzed in [13-15]. According to the special structure and related theories of the motor, the equivalent model of the motor temperature rise was established, and the correctness of the model was verified by experiments in [16-18]. The influence of winding temperature rise on mechanical characteristics, such as copper loss, iron loss, and efficiency, was analyzed by the finite element method in [19]. The characteristics of the eight constants that vary with the motor temperature and the residual flux density are shown in [20].The abovementioned methods have studied and analyzed the influencing factors of motor temperature rise and the mutual influence between motor temperature rise and motor, and established an equivalent model. However, they have not studied the specific control strategy and temperature rise characteristics of patrol robot during speed control, and with the support of literature review, no research has been found on the control strategy and temperature rise characteristics of high-voltage patrol robot during speed control. Therefore, it is particularly important to propose an optimal control method of unpowered downhill speed and energy recovery based on the temperature rise characteristics of the walking motor.

The novelty of this paper lies in the fact that an optimal control method of unpowered downhill speed and energy recovery based on the temperature rise characteristics of the walking motor is proposed for the first time. Firstly, the thermal equivalent circuit model of the walking motor is established, and the mapping relationship between the armature winding temperature and environmental temperature of the walking motor is solved. The influence of armature winding temperature on unpowered downhill speed and energy recovery control strategy of the robot is analyzed. According to the temperature of front and rear wheel walking motors and the temperature difference between them, the optimal control strategy of unpowered downhill speed and energy recovery of the robot is put forward by adjusting the duty ratio of the energy consumption speed control system and the front wheel feedback brake distribution factor, and the temperature difference between the front and rear wheel walking motors is reduced. Through the experimental analysis on the simulated line, it is verified that the unpowered downhill speed and energy recovery optimization control method based on the temperature rise characteristics of the walking motor can effectively reduce the temperature difference between the front and rear wheels.

\section{Line Condition and Circuit Model}

2.1. Line Inspection Robot Line Conditions. As shown in Figure 1, it is a simplified model of the running environment of the high-voltage inspection robot in complexity microgrid networks. Most of the high-voltage transmission lines are typical catenary structures. Between two adjacent towers, the lines are downhill first and then uphill. The downhill section provides conditions for the robot to realize unpowered downhill speed control and energy recovery. In the downhill process, it is necessary to control the speed of the inspection robot. In order to prevent the motor from being damaged due to the rapid temperature rise in the speed control process, this paper proposes an optimal control strategy of unpowered downhill speed and energy recovery based on the temperature rise characteristics of the walking motor. The configuration diagram of inspection robot is shown in Figure 2, and the walking motor is the MaxonRE40 motor.

\subsection{Thermal Equivalent Circuit Model of the Walking Motor.} In order to ensure the normal operation of the robot in the process of unpowered downhill, and to avoid the motor damage caused by excessive temperature in the process of braking and speed control, the armature winding temperature of the walking motor needs to be monitored in real time. In the process of patrol inspection, the heat sources of temperature rise of the walking motor include copper loss on winding, air resistance loss, and mechanical loss, among which copper loss on winding accounts for the vast majority. Figure 3 is the curve of resistance $R_{T_{W}}$ of armature winding changing with temperature in the range of $-50^{\circ} \mathrm{C}-200^{\circ} \mathrm{C}$.

It can be seen from Figure 3 that the resistance $R_{T_{W}}$ of the armature winding of motor changes linearly with temperature, and the resistance $R_{T_{W}}$ of the armature winding at temperature $T_{W}$ is

$$
R_{T_{W}}=R_{25} \cdot\left(1+\alpha_{C u}\left(T_{W}-25\right)\right),
$$

where $R_{25}$ is the resistance value of the armature winding of the motor at $25^{\circ} \mathrm{C}$ and $\alpha_{\mathrm{Cu}}$ is the temperature coefficient of copper, which is $0.0039 \mathrm{~K}^{-1}$. Accordingly, the resistance value of the armature winding of the motor can also be calculated with reference to the external environment at temperature $T_{A}$, and the formula (1) can be expressed as

$$
R_{T_{w}}=R_{T_{A}} \cdot\left(1+\alpha_{C u}\left(T_{w}-T_{A}\right)\right),
$$

where $R_{T_{A}}$ is the resistance value of the armature winding of the motor at temperature $T_{A}$, and the unit is $\Omega$.

Figure 4 is a heat flow diagram and its equivalent circuit between the armature winding, the shell, and the external environment of the motor, where $T_{w}$ is the temperature of 


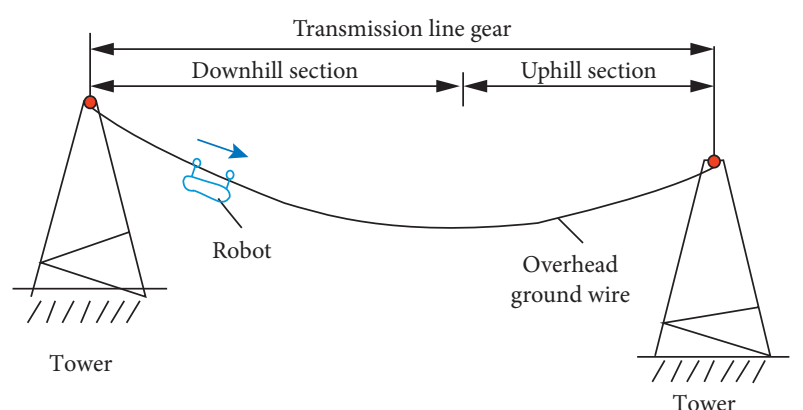

FIGURE 1: Simplified model of the robot's operating environment.

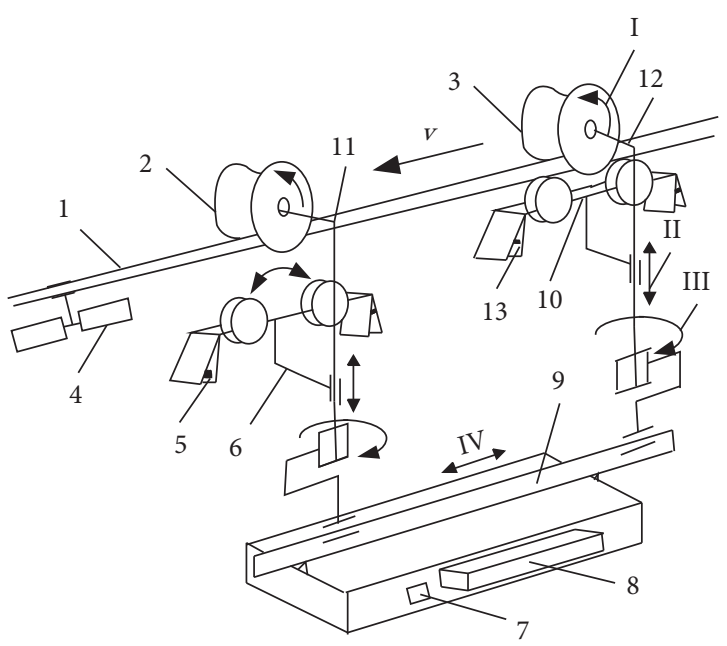

Figure 2: Configuration diagram of the patrol robot for crossing obstacles. (1) Ground wire; (2) front wheel; (3) rear wheel; (4) antivibration hammer; (5) forearm collision detection sensor; (6) forearm pressing mechanism; (7) switching circuit; (8) energy storage battery; (9) body; (10) rear arm pressing wheel; (11) forearm; (12) rear arm; (13) rear arm collision detection sensor.

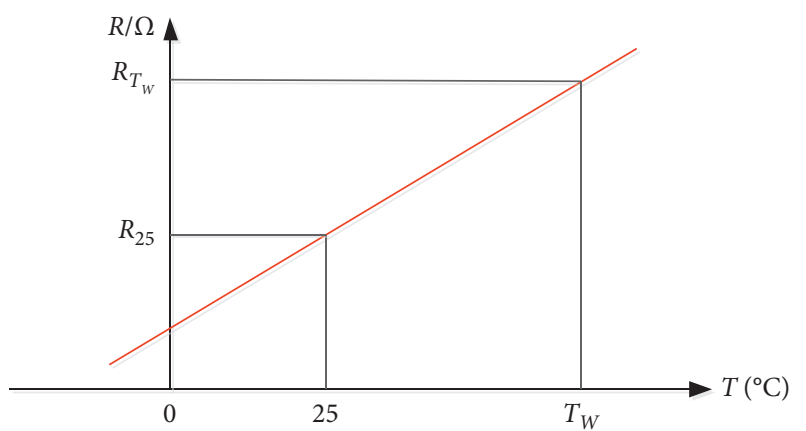

FIGURE 3: Curve of armature winding resistance changing with temperature.

the armature winding of the motor in $\mathrm{K} ; T_{s}$ is the temperature of motor stator and casing, in $\mathrm{K} ; T_{A}$ is the ambient temperature in $\mathrm{K}$; the temperature difference between armature winding of the motor and ambient temperature is $\Delta T_{w}\left(\Delta T_{w}=T_{w}-T_{A}\right)$, which is similar to the voltage difference $U_{1}$ in equivalent circuit. The temperature difference

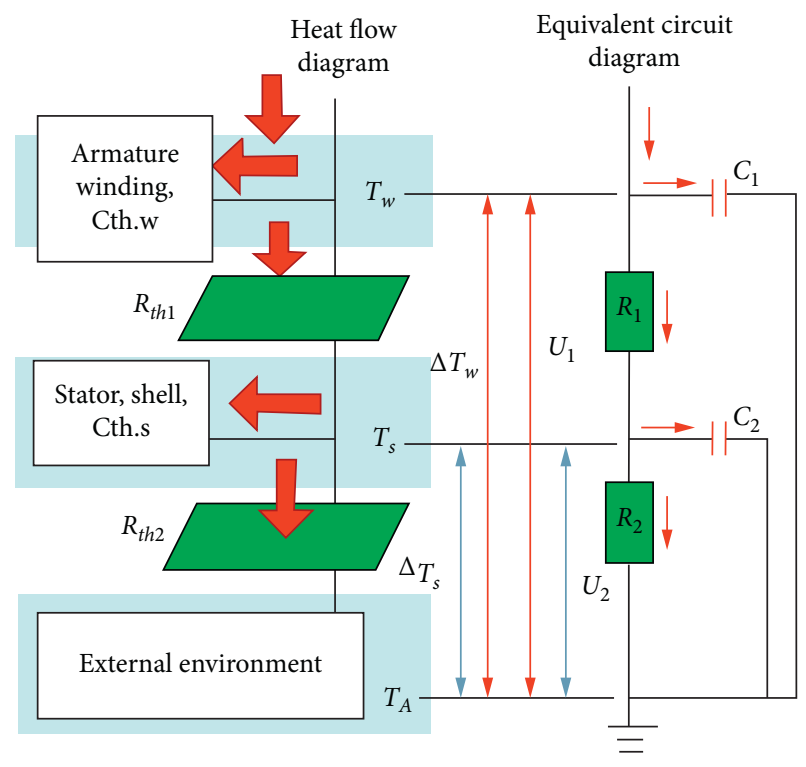

FIgUre 4: Heat flow diagram and equivalent circuit diagram.

between stator, casing, and ambient temperature of motor is $\Delta T_{s}\left(\Delta T_{s}=T_{s}-T_{A}\right)$, which is similar to the voltage difference $U_{2}$ in an equivalent circuit.

Joule heat $P_{v}$ is generated when the motor winding flows through current, which changes the temperature of the motor winding by $\Delta T_{w}^{\prime}$, resulting in a temperature difference between the motor winding and the motor stator and casing. Heat flows to the motor stator through air in the form of thermal convection. The thermal resistance between the armature winding and the stator and casing is $R_{t h_{1}}$, which is similar to the resistance $R_{1}$ in an equivalent circuit. The absorbed energy $Q_{w}$ of the motor armature winding is

$$
Q_{w}=C_{C u} \cdot m_{w} \cdot \Delta T_{w}^{\prime}=C_{t h . w} \cdot \Delta T_{w}^{\prime},
$$

where $C_{C u}$ is the specific heat capacity of copper, $C_{C u}=380(\mathrm{j} / \mathrm{kgk}) ; m_{w}$ is the mass of armature winding of motor, in $\mathrm{kg}$; and $C_{t h . w}$ is the heat capacity of motor armature, and the unit is $\mathrm{J} / \mathrm{K}$.

Similarly, when the motor stator and shell absorb the heat generated by motor windings, the temperature of the stator and shell rises. For convenience of analysis, it is assumed that the permanent magnets, shell, and flange of the motor have the same temperature. When there is a temperature difference between the motor stator and shell and the external environment, the heat will flow from the motor shell to the external environment. The thermal resistance between the stator and shell and the external environment is $R_{t h_{2}}$, which is similar to the resistance $R_{2}$ in the equivalent circuit. Heat $Q_{s}$ absorbed by motor stator and casing is as follows:

$$
Q_{s}=C_{F_{e}} \cdot m_{s} \cdot \Delta T_{s}^{\prime}=C_{t h . w} \cdot \Delta T_{s}^{\prime} .
$$

In the formula, $C_{F_{e}}$ is the specific heat capacity of iron in $\mathrm{j} /(\mathrm{kg} \cdot \mathrm{K}) ; m_{s}$ is the mass of motor stator and casing, in $\mathrm{kg}$; $C_{t h . s}$ is the heat capacity of motor armature, in $\mathrm{J} / \mathrm{K}$; and $\Delta T_{s}^{\prime}$ is the temperature change of motor stator and casing, in $k$. 


\section{The Influence of Temperature Rise on the Motor}

According to the motor manual, the rated current $I_{N}$ corresponds to the maximum allowable continuous current, which has a great relationship with the winding. The rated current of the thin wire winding is smaller than that of the thick wire winding, and the rated torque corresponding to the rated current of different winding series motors of the same model is almost the same. Under the standard environment (ambient temperature $25^{\circ} \mathrm{C}$, no radiator on the motor flange, natural convection), the maximum continuous current makes the armature winding reach the maximum allowable temperature $T_{\max }$, and the higher current will cause the winding temperature to be too high.

Figure 5 shows the corresponding relationship between motor winding temperature and running time. It can be seen from the figure that

(1) When the armature working current $I>I_{N}$, or the output torque $M>M_{N}$, the final temperature of the motor winding will exceed the maximum allowable temperature $T_{\max }$; therefore, before the final temperature reaches, the motor operation must be stopped, resulting in the limited running time of the motor.

(2) When the armature working current $I=I_{N}$ or the output torque $M>M_{N}$, the final temperature of the motor winding will reach the maximum allowable temperature $T_{\max }$.

(3) When the motor armature working current is $I<I_{N}$, or the output torque is $M<M_{N}$, the final temperature of the motor winding will be lower than the maximum allowable temperature $T_{\max }$, so the motor running time will not be limited under this condition.

The parameters of the motor manual are obtained under the ambient temperature of $25^{\circ} \mathrm{C}$ and standard assembly conditions. It can be seen from formula (3) that when the temperature of armature winding changes, the resistance of armature winding will also change. Similarly, the rated current and rated torque of motor will also change for different ambient temperatures. According to the formula of temperature difference between armature winding of motor and external environment:

$$
\begin{gathered}
T_{\text {max }}-25^{\circ} \mathrm{C}=\left(R_{t h 1}+R_{t h 2}\right) \cdot R_{T_{\max }} \cdot I_{N}^{2}\left(25^{\circ} \mathrm{C}\right), \\
T_{\max }-T_{A}=\left(R_{t h 1}+R_{t h 2}\right) \cdot R_{T_{\max }} \cdot I_{N}^{2}\left(T_{A}\right) .
\end{gathered}
$$

In formulas (5) and (6), $I_{N}\left(25^{\circ} \mathrm{C}\right)$ is the rated current of the motor when the ambient temperature is $25^{\circ} \mathrm{C}$, and the unit is $\mathrm{A} ; R_{T_{\max }}$ is the resistance value of motor winding at the maximum allowable temperature $T_{\max }$, and the unit is $\Omega$; $I_{N}\left(T_{A}\right)$ is the rated current of the motor when the ambient temperature is $t$, and the unit is A. According to formulas (5) and (6),

$$
\begin{aligned}
\frac{T_{\max }-25^{\circ} \mathrm{C}}{T_{\max }-T_{A}} & =\frac{\left(R_{t h 1}+R_{t h 2}\right) \cdot R_{T_{\max }}}{\left(R_{t h 1}+R_{t h 2}\right) \cdot R_{T_{\max }}} \frac{I_{N}^{2}\left(25^{\circ} C\right)}{I_{N}^{2}\left(T_{A}\right)}=\frac{I_{N}^{2}\left(25^{\circ} \mathrm{C}\right)}{I_{N}^{2}\left(T_{A}\right)}, \\
I_{N}\left(T_{A}\right) & =I_{N}\left(25^{\circ} \mathrm{C}\right) \sqrt{\frac{T_{\max }-T_{A}}{T_{\text {max }}-25^{\circ} \mathrm{C}}}
\end{aligned}
$$

The values of thermal resistance and maximum continuous current in the motor parameter table are obtained by installing the motor on a vertical plastic plate and after a series of tests. Mounting the motor on a radiator will significantly reduce the thermal resistance $R_{t h 2}$ between the motor casing and the environment. For the motor of model MaxonRE40, the end face of the motor has a metal flange mounting hole. If it is mounted on a good metal heat conductor, the thermal resistance $R_{t h 2}$ can be reduced by $50 \%$. Therefore, in specific applications, the change of thermal resistance $R_{t h 2}$ must be determined by actual installation and environmental conditions, and $R_{t h 2 . m o d}$ is defined as the corrected thermal resistance between the motor casing and the environment under different installation conditions. Figure 6 shows a heat flow diagram between the motor housing and the environment.

It can be seen from the figure that in the practical application process, the real thermal resistance of the motor is expressed by the corrected thermal resistance $R_{t h 2 \text { mod }}$ between the motor casing and the external environment. If the corrected thermal resistance $R_{t h 2 \text { mod }}$ between the motor casing and the external environment is known, the rated current $I_{N}\left(T_{A}\right)$ of the motor corresponding to different environmental temperatures can be calculated in a simple and accurate way. The formula for $R_{t h 2 . \bmod }$ is

$$
R_{t h 2 \text { mod }}=\Delta T_{S} \cdot \frac{1-\alpha_{C u} \cdot R_{t h 1} \cdot R_{T_{A}} \cdot I^{2}}{R_{T_{A}} \cdot I^{2} \cdot\left(1+\alpha_{C u} \Delta T_{S}\right)} .
$$

According to formulas (5) and (6), the rated current $I_{N}\left(T_{A}\right)$ and rated output torque $M_{N}\left(T_{A}\right)$ of the motor at different ambient temperatures $T_{A}$ are

$$
\begin{gathered}
I_{N}\left(T_{A}\right)=I_{N}\left(25^{\circ} \mathrm{C}\right) \cdot \sqrt{\frac{T_{\max }-T_{A}}{T_{\text {max }}-25^{\circ} \mathrm{C}} \cdot \frac{R_{t h 1}+R_{t h 2}}{R_{t h 1}+R_{t h 2 . \bmod }}}, \\
M_{N}\left(T_{A}\right)=M_{N}\left(25^{\circ} \mathrm{C}\right) \cdot \sqrt{\frac{T_{\max }-T_{A}}{T_{\max }-25^{\circ} \mathrm{C}} \cdot \frac{R_{t h 1}+R_{t h 2}}{R_{t h 1}+R_{t h 2 . \bmod }}},
\end{gathered}
$$

where $M_{N}\left(25^{\circ} \mathrm{C}\right)$ is the rated output torque of the motor at $25^{\circ} \mathrm{C}$, and the unit is $\mathrm{Nm}$.

Let $k_{M}=\left(M_{N}\left(T_{A}\right) / M_{N}\left(25^{\circ} C\right)\right)$ be the rated torque variation coefficient and $k_{A}=\left(I_{N}\left(T_{A}\right) / I_{N}\left(25^{\circ} C\right)\right)$ be the rated current variation coefficient, as shown in Figure 7 , which shows the curves of $k_{A}$ and $k_{M}$ under different ambient temperatures. It can be seen from the figure that with the increase of ambient temperature, the rated current and torque of the motor will decrease, and after the temperature exceeds $100^{\circ} \mathrm{C}$, the decline rate of the rated current 


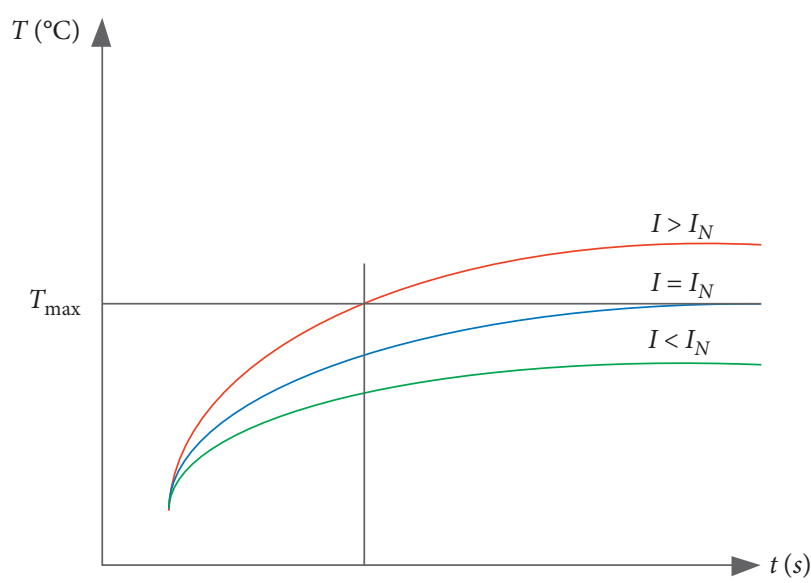

(a)

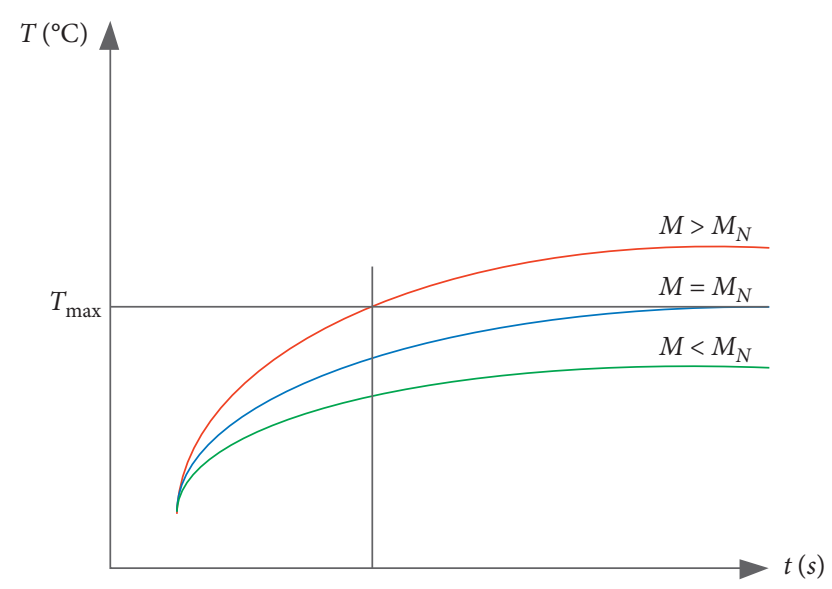

(b)

FIGURE 5: Corresponding relationship between motor winding temperature and running time. (a) Winding temperature variation curves under different working currents. (b) Winding temperature variation curves under different output torques.

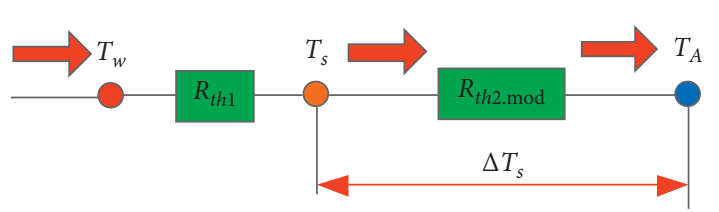

Figure 6: Heat flow diagram between motor casing and environment.

and torque of the motor will increase rapidly; under the same environmental temperature, if the motor is installed on a good heat conductor, the thermal resistance between the motor shell and the external environment will be reduced, thus increasing the rated current and torque of the motor.

\section{Analysis of the Influence of Temperature Rise on Control Strategy}

Figure 8 shows the force analysis of the front and rear wheels of the robot in the process of unpowered downhill. Figure $8(\mathrm{a})$ shows the force analysis of the front wheel of the robot. $F_{P 1}$ and $F_{V 1}$ are the forces of the robot's forearms on the front wheel in the tangential direction of the ground wire and in the direction perpendicular to the ground wire, respectively, and the unit is $\mathrm{N} ; G_{w 1}$ is the gravity on the front wheel, in $\mathrm{N}$. The front wheel mass is $m_{1}$ in $\mathrm{kg} ; w_{1}$ is the angular velocity of the front wheel in $\mathrm{rad} / \mathrm{s} ; T_{1}$ is the braking torque generated by energy consumption braking of front wheels, and the unit is $\mathrm{Nm}$. Figure $8(\mathrm{~b})$ shows the stress analysis of the rear wheel of the robot, and the meaning of each parameter is the same as that of the Figure 8(a).

From the force analysis in Figure 8, it can be seen that the torque of the front and rear wheels of the robot $O_{1}^{\prime}$ and $O_{2}^{\prime}$ are

$$
\left\{\begin{array}{l}
F_{X 1} r-T_{1}-T_{f 1}=J_{1} \frac{\mathrm{d} \omega_{1}}{\mathrm{~d} t}, \\
F_{X 2} r-T_{2}-T_{f 2}=J_{2} \frac{\mathrm{d} \omega_{2}}{\mathrm{~d} t} .
\end{array}\right.
$$

The total braking torque generated by the front and rear wheels of the robot without power and constant-speed downhill is

$$
T_{1}+T_{2}=\left(\frac{G \tan \theta}{\sqrt{1+\tan ^{2} \theta}}-\frac{G f}{\sqrt{1+\tan ^{2} \theta}}-\frac{\rho C_{D} A}{2} v^{2}\right) r
$$

It can be seen from the above formula that the braking torques $T_{1}$ and $T_{2}$ of the front and rear wheel traveling motors are

$$
\begin{aligned}
& T_{1}=i \eta_{T} \eta_{m} k_{t} i_{a 1}=i \eta_{T} \eta_{m} k_{t} \frac{U}{R_{T_{w 1}}+R_{s}}=\frac{i \eta_{T} \eta_{m} k_{t} k_{e} n}{R_{T_{A}} \cdot\left(1+\alpha_{C u}\left(T_{w 1}-T_{A}\right)\right)+R_{s}} \\
& T_{2}=\frac{u i \eta_{T} \eta_{m} k_{t} k_{e} n}{R_{T_{w 2}}+R_{Z}}=\frac{u i \eta_{T} \eta_{m} k_{t} k_{e} n}{R_{T_{A}} \cdot\left(1+\alpha_{C u}\left(T_{w 2}-T_{A}\right)\right)+R_{Z}}
\end{aligned}
$$

In formula (13), $\eta_{T}$ is the transmission efficiency of motor reducer; $\eta_{m}$ is the working efficiency of the motor. A current sensor is used to detect the charging current ial of the front wheel to the battery, where $k_{e}$ is the electromotive force constant, $k_{t}$ is the torque constant, $n$ is the motor speed, $u$ is the PWM wave duty ratio, $\mathrm{i}$ is the circuit current, 


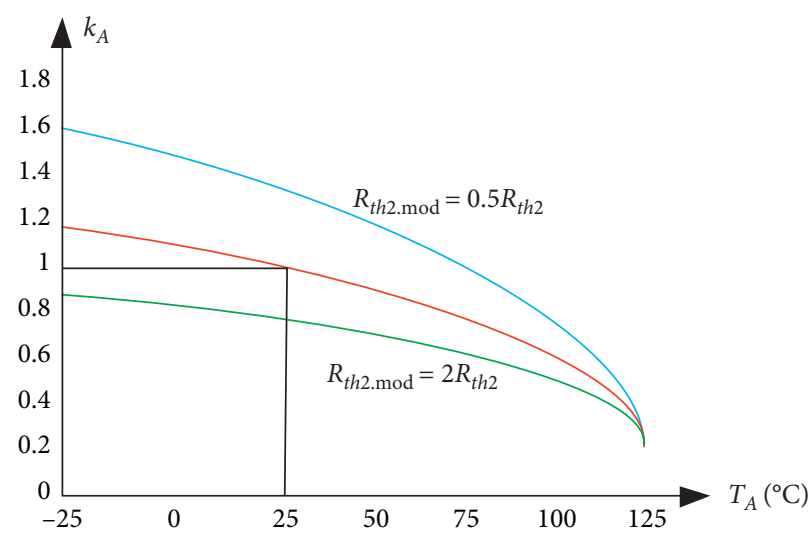

(a)

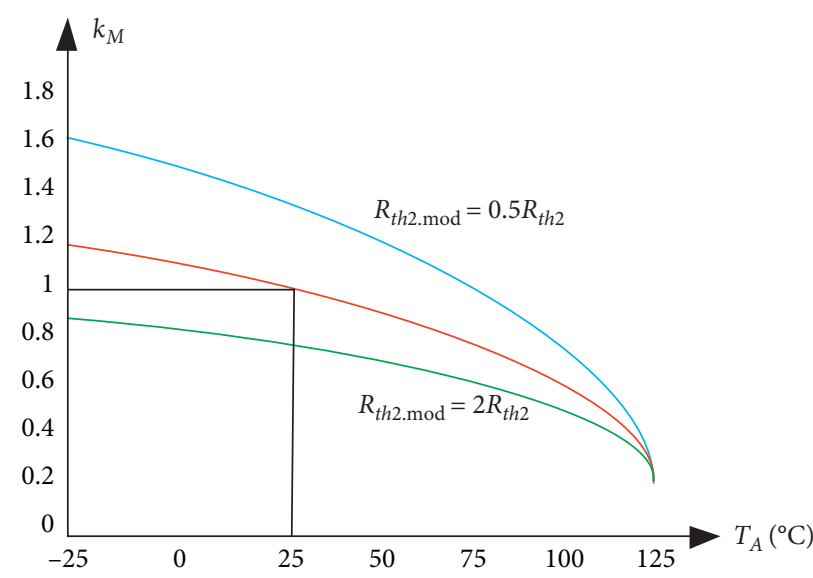

(b)

FiguRE 7: Variation curves of $k_{A}$ and $k_{M}$ under different ambient temperatures. (a) $k_{A}$ change curve at different ambient temperatures. (b) $k_{M}$ change curve at different ambient temperatures.

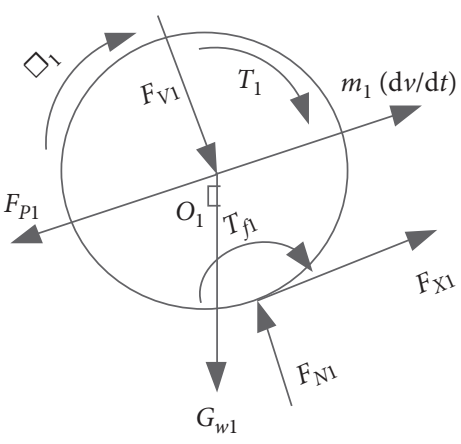

(a)

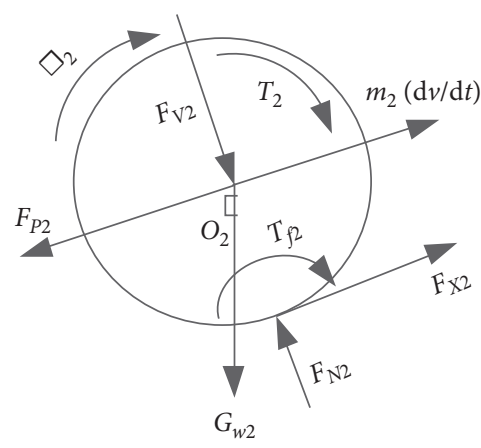

(b)

FIGURE 8: Force analysis of front and rear wheels of robot. (a) Force analysis of robot front wheel. (b) Force analysis of robot rear wheel.

$R_{Z}$ is the energy consumption resistance, $R_{s}$ is the internal resistance of the robot compound power supply, and the unit is $\omega$. In order to facilitate the study of the influence of the walking motor temperature on unpowered downhill speed control and energy recovery, the influence of the internal resistance $R_{s}$ of the compound power supply with temperature and SOC is not considered; $T_{w 1}$ is the armature winding temperature of the robot front wheel walking motor, and the unit is $k$; in formula (14), $T_{w 2}$ is the armature winding temperature of the robot rear wheel walking motor, and the unit is $k$; it can be seen from formulas (13) and (14) that the braking torque provided by the front and rear wheel traveling motors decreases with the increase of temperature during the unpowered constant speed downhill of the robot, and the braking torque required by the energy consumption braking of the rear wheel traveling motors will increase in order to keep the robot going downhill at a constant speed without power.

When the robot goes downhill at a constant speed without power, the duty ratio $u_{0}$ of the PWM wave of the rear wheel energy consumption braking circuit is

$$
u_{0}=\frac{\left(R_{T_{w 2}}+R_{Z}\right) r}{i \eta_{T} \eta_{m} k_{t} k_{e} n}\left(\frac{G \tan \theta}{\sqrt{1+\tan ^{2} \theta}}-\frac{G f}{\sqrt{1+\tan ^{2} \theta}}-\frac{\rho C_{D} A}{2} v^{2}\right)-\frac{i_{a 1}}{k_{e} n}
$$

According to equation (15), when the slope of ground wire is $\theta$, the robot goes downhill unpowered at a constant speed $v$, and the armature resistance $R_{T_{w 2}}$ will increase linearly as the temperature of the armature winding of the rear wheel traveling motor rises. In order to keep the robot going downhill at a constant speed without power, the duty 
ratio $u_{0}$ of PWM wave in the energy consumption control system of the rear wheel walking motor will also increase linearly. With the increase of duty ratio $u_{0}$ of the PWM wave in energy consumption speed control system, the current flowing through the armature winding of rear wheel walking motor will also increase, the Joule heat generated by armature winding will increase, and the internal heat balance of motor will be destroyed, which will further cause the temperature of rear wheel walking motor to rise.

It can be seen from formula (9) that the rated current $I_{N}\left(T_{A}\right)$ of the motor decreases gradually with the temperature rise of the motor. To ensure the safety of the robot walking motor and avoid the damage of the walking motor in the process of unpowered downhill, the braking current of the two walking motors should be less than the rated current $I_{N}\left(T_{A}\right)$.

\section{Strategy Optimization}

According to the above analysis, it can be seen that the change of armature winding temperature of the walking motor has an impact on its braking torque, rated torque, and rated current. Therefore, with the change of armature winding temperature of the walking motor, the control strategy of unpowered downhill speed and energy recovery needs to be optimized accordingly in order to make the robot run smoothly and safely at a constant speed. In order to recover the feedback braking energy to the maximum extent, the feedback braking distribution factor $\lambda$ should be made as large as possible without considering the slippage of the front and rear wheels of the robot. In order to make the robot go downhill at a constant speed without power, the PWM duty ratio $u_{0}$ of the rear wheel energy consumption braking speed control system and the front wheel feedback braking distribution factor $\lambda$ are, respectively,

$$
\begin{aligned}
u_{0}\left(\theta, v, T_{w 1}, T_{w 2}\right)= & \frac{\left(R_{T_{A}}\left(1+\alpha_{C u}\left(T_{w 2}-T_{A}\right)\right)+R_{Z}\right) r}{i \eta_{T} \eta_{m} k_{t} k_{e} n}\left(\frac{G \tan \theta}{\sqrt{1+\tan ^{2} \theta}}-\frac{G f}{\sqrt{1+\tan ^{2} \theta}}-\frac{\rho C_{D} A}{2} v^{2}\right) \\
& -\frac{1}{R_{s}+R_{T_{A}}\left(1+\alpha_{C u}\left(T_{w 1}-T_{A}\right)\right)}, \\
\lambda\left(\theta, v, T_{w 1}\right)= & \frac{i \eta_{T} \eta_{m} k_{t} k_{e} n}{r\left(G \sin \theta-G f \cos \theta-\left(\rho C_{D} A v^{2} / 2\right)\right)\left(R_{T_{w 1}}+R_{s}\right)} \\
= & \frac{i \eta_{T} \eta_{m} k_{t} k_{e} n}{r\left(G \sin \theta-G f \cos \theta-\left(\rho C_{D} A v^{2} / 2\right)\right)\left(R_{T_{A}}\left(1+\alpha_{C u}\left(T_{w 1}-T_{A}\right)\right)+R_{s}\right)} .
\end{aligned}
$$

It can be seen from formulas (16) and (17) that the PWM wave duty ratio $u_{0}$ and the front wheel feedback brake distribution factor $\lambda$ of the rear wheel energy consumption brake speed control system are related to the slope $\theta$ of the line where the robot is located, the downhill speed $v$, and the armature winding temperatures $T_{w 1}$ and $T_{w 2}$ of the front and rear wheel traveling motors. Therefore, considering the influence of the walking motor armature winding temperature on PWM duty ratio $u_{0}$ and front wheel feedback braking distribution factor $\lambda$ of energy consumption braking speed control system, it is necessary to monitor the walking motor armature winding temperature $T_{w 1}$ and $T_{w 2}$ in real time, and optimize unpowered constant speed downhill control strategy and feedback braking distribution factor $\lambda$.

The highest working temperature of the armature winding of the walking motor is $T_{\max }$. In order to avoid damage caused by excessive temperature during unpowered downhill, the armature winding temperatures $T_{w 1}$ and $T_{w 2}$ of front and rear wheels should not be higher than that of the robot front and rear wheels $\left(T_{w 1} \leq T_{\max }, T_{w 2} \leq T_{\max }\right)$, In order to avoid service life difference caused by large temperature difference, the temperature difference $(\Delta T)$ of the armature winding of front and rear wheels should meet the following requirements:
In formula (18), $\Delta T_{\max }$ is the maximum allowable temperature difference between armature windings of front and rear wheel traveling motors, and the unit is $k$. When the total braking torque provided by the robot front and rear wheel traveling motors meets the condition of unpowered constant speed downhill, the feedback braking distribution factor $\lambda$ is adjusted to distribute the braking torque required by the robot front and rear wheel traveling motors for unpowered constant speed downhill, so as to achieve the purposes of reducing the braking current flowing through the armature winding of the traveling motor with high temperature and improving the braking current of the armature winding of the traveling motor with low temperature, so that the temperature difference between the armature windings of the front and rear wheels is $\Delta T \leq \Delta T_{\max }$. Figure 9 shows a diagram of unpowered downhill optimization control strategy based on the walking motor temperature, and the specific implementation strategy is as follows:

During the unpowered and constant-speed downhill process of the robot, the temperature detection system detects the aluminum flange temperatures $T_{A 1}$ and $T_{A 2}$ of the front and rear wheel traveling motors in real time, and 


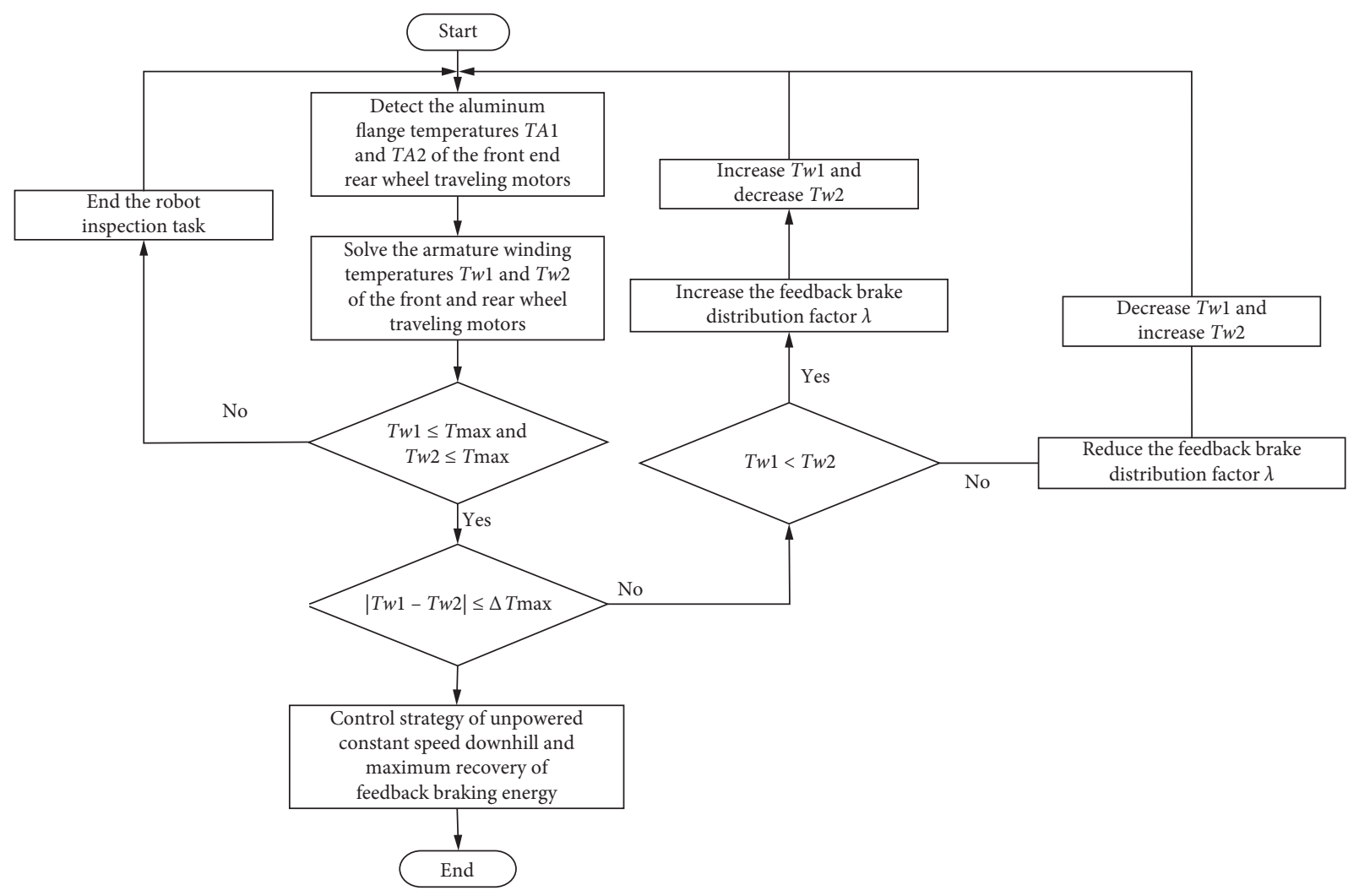

FIGURE 9: Unpowered downhill optimization control strategy based on walking motor temperature.

solves the armature winding temperatures $T_{w 1}$ and $T_{w 2}$ of the front and rear wheel traveling motors through the temperature difference between the motor armature windings and the external environment. When $T_{w 1}>T_{\max }$ or $T_{w 2} \leq T_{\text {max }}$, the armature winding temperature exceeds the highest working temperature of the traveling motors. In order to avoid the damage of the traveling motors caused by excessive temperature and ensure the safe and stable operation of the robot on the transmission line, the robot should immediately finish the inspection task and wait for the armature winding temperatures of the two traveling motors to drop to normal. When $T_{w 1} \leq T_{\max }$ and $T_{w 2} \leq T_{\max }$, the control strategy of the front wheel feedback brake distribution factor for the temperature difference between the armature windings of the front and rear wheel traveling motors is as follows:

(1) When $\Delta T=\left|T_{w 1}-T_{w 2}\right|>\Delta T_{\max }$ and $T_{w 1}<T_{w 2}$, on the premise that the total braking torque of the front and rear wheels is unchanged when the robot goes downhill at a constant speed without power, the feedback braking torque of the front wheels is increased by increasing the distribution factor $\lambda$, and the energy consumption braking torque of the rear wheels is reduced, so that the temperature difference of armature windings of the front and rear wheels traveling motors satisfies $\Delta T \leq \Delta T_{\max }$.

(2) When $\Delta T=\left|T_{w 1}-T_{w 2}\right|>\Delta T_{\max }$ and $T_{w 1}>T_{w 2}$, by reducing the front wheel feedback braking distribution factor $\lambda$, the front wheel feedback braking torque is reduced, and the rear wheel energy consumption braking torque is increased, so that the temperature difference between the armature windings of the front and rear wheel traveling motors meets $\Delta T \leq \Delta T_{\max }$.

(3) When $\Delta T=\left|T_{w 1}-T_{w 2}\right| \leq \Delta T_{\max }$, the robot implements the unpowered constant speed downhill control strategy, and increases the front wheel feedback braking distribution factor $\lambda$, so as to recover the feedback braking energy to the maximum extent.

\section{System Preparation and Experimental Results}

Figure 10 shows the block diagram of the walking motor temperature detection system of the inspection robot. During the unpowered downhill process of the robot, the front and rear wheel temperature sensors, respectively, detect the aluminum flange temperatures of the front and rear wheel walking motors, obtain the temperature information through the ARM microprocessor, calculate the motor armature winding temperature by the walking motor armature winding temperature analysis system, and optimize the unpowered downhill speed and energy recovery control strategy according to the front and rear wheel walking motor armature winding temperature. Because the robot performs patrol inspection on the high-voltage transmission line, in order to enable the ground operators to 


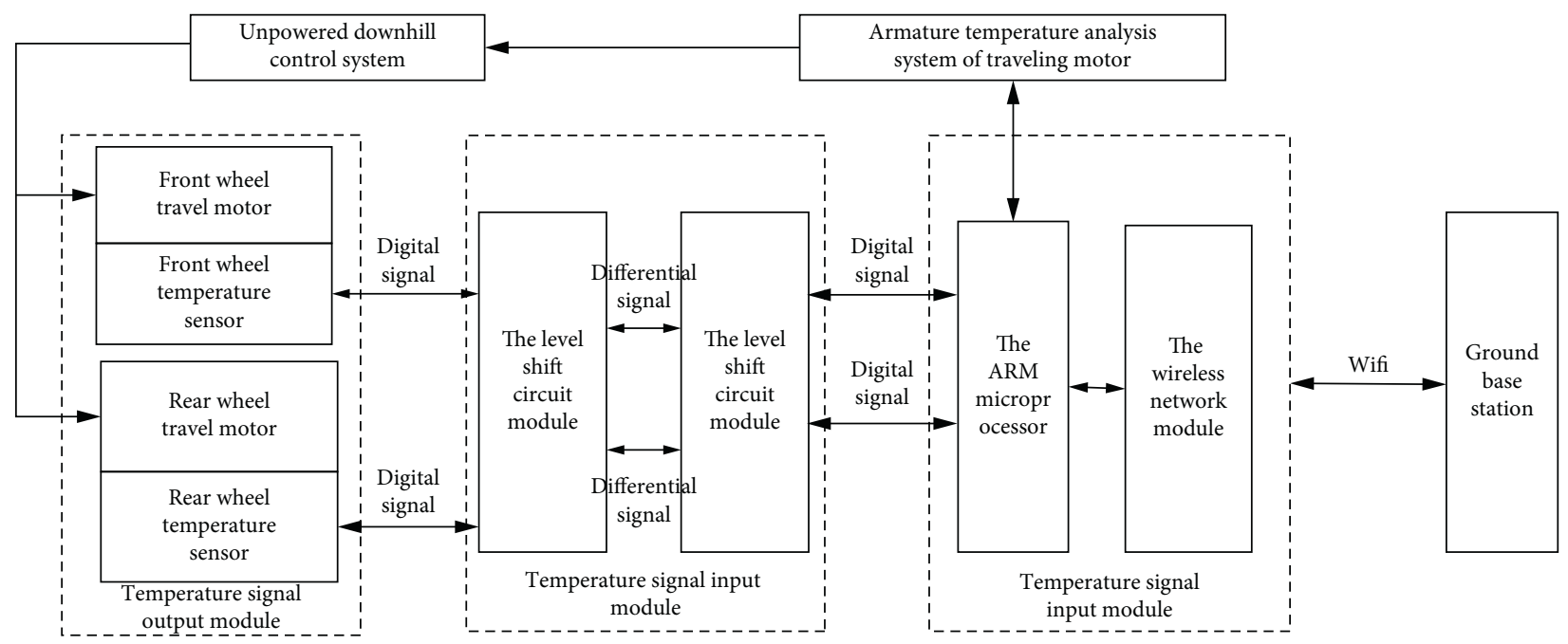

FIGURE 10: Block diagram of temperature detection system.

monitor the temperature of the front and rear wheel walking motors in real time, the wireless network module is adopted to transmit the temperature information of the front and rear wheel walking motors to the ground base station through wireless WIFI. Figure 11 shows the temperature detection system of the robot walking motor.

Figure 12 is the field experiment running diagram of the robot between \#114 and \#119 tower sections. Among them, between \#114 and \#117 towers, the height difference between two adjacent towers is negative, so the distance of the robot in the downhill section between two adjacent towers is higher than that in the uphill section; in \#117-\#119 towers, if the height difference between two adjacent towers is positive, the distance of the robot in the uphill section is higher than that in the downhill section between adjacent towers, as shown in Figure 13, which is the schematic diagram of robot running between \#114 and \#119 towers.

Figure 14 is the temperature change curve of the front and rear wheel traveling motors of the robot in the servo drive mode between \# 114 and \# 119 towers. It can be seen from the figure that the temperature of the front and rear wheel traveling motors of the robot gradually rises as the robot performs the inspection task between the sections, and when the temperature of the walking wheel reaches $80^{\circ} \mathrm{C}$ (the highest temperature of the encoder working normally is $85^{\circ} \mathrm{C}$ ), the robot stops performing the inspection task, and then starts to perform the inspection task when the temperature of the walking wheel drops to a safe temperature. Taking the robot's patrol task between towers \#115 and \#116 as an example, the distance of the downhill section of the robot is higher than that of the uphill section, and the height difference between adjacent towers in this section is the largest. It can be seen from the figure that the temperature rise of the rear wheel walking motor is slightly faster than that of the front wheel in the downhill section, and the maximum temperature difference between the front and rear wheel walking motors is $1.2^{\circ} \mathrm{C}$. Therefore, when the robot goes downhill in servo drive mode, the downhill resistance provided by the rear wheel walking motor is slightly higher than that of the front wheel. Taking the robot's patrol inspection task between \#118 and \#119 towers as an example, the uphill section between the sections has the longest distance. It can be seen from the figure that the temperature of the front wheel walking motor is slightly faster than that of the rear wheel in the uphill section, so when the robot climbs between the sections, the servo driving force of the front wheel is higher than that of the rear wheel.

Figure 15 is the temperature change curve of the front and rear wheel walking motors of the robot in the unpowered constant speed downhill mode. It can be seen from the figure that the temperature difference between the front and rear wheel walking motors has a greater increase compared with the whole operation of the robot in the servo drive mode. In the unpowered downhill mode, the temperature rise of the rear wheel traveling motor is faster than that of the front wheel; therefore, in the unpowered downhill mode, the downhill braking force provided by the rear wheel is higher than that of the front wheel, which makes the temperature difference between the front and rear wheel traveling motors gradually increase. In the uphill stage, the robot switches to servo drive mode, and the driving force provided by the front wheel is higher than that of the rear wheel, so that the temperature difference between the front and rear wheels gradually decreases.

Figure 16 shows the temperature change curve of walking wheels optimized by unpowered downhill strategy based on the temperature of walking wheels. It can be seen from the figure that the temperature difference between the front and rear wheels of walking motors is $8.8^{\circ} \mathrm{C}$ after the robot inspects the \#116-\#117 gears, and the robot performs unpowered downhill strategy optimization based on the temperature of walking wheels in the downhill section between \#117 and \#118 gears. After the robot completes unpowered downhill execution, the temperature difference between the front and rear wheels of walking motors drops to $6^{\circ} \mathrm{C}$. Therefore, if the temperature difference between the front and rear wheel traveling motors exceeds $8^{\circ} \mathrm{C}$, the robot starts the unpowered downhill strategy optimization based 


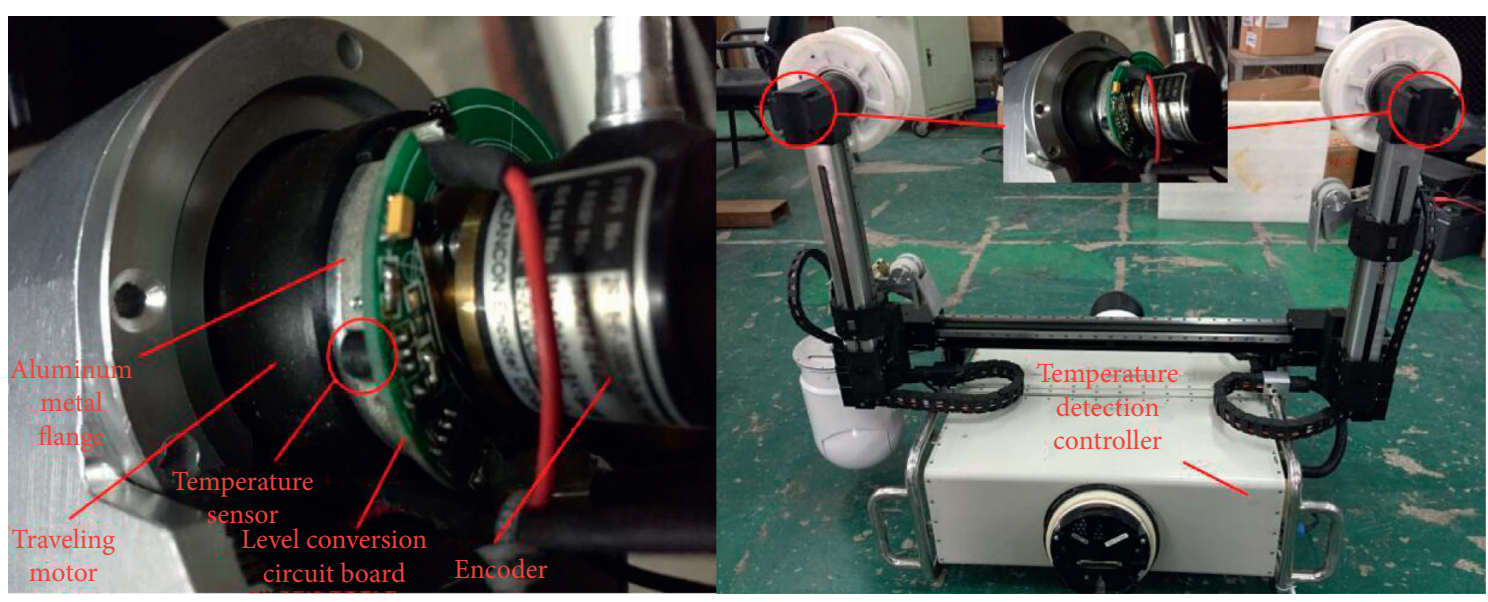

Figure 11: Temperature detection system of the walking motor.

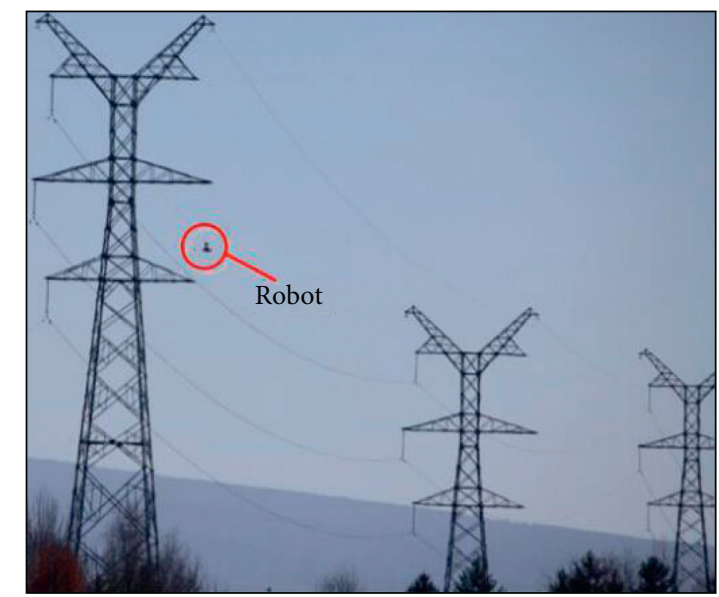

FIgURE 12: The robot's field experiment operation diagram between \#114 and \#119 pole towers.

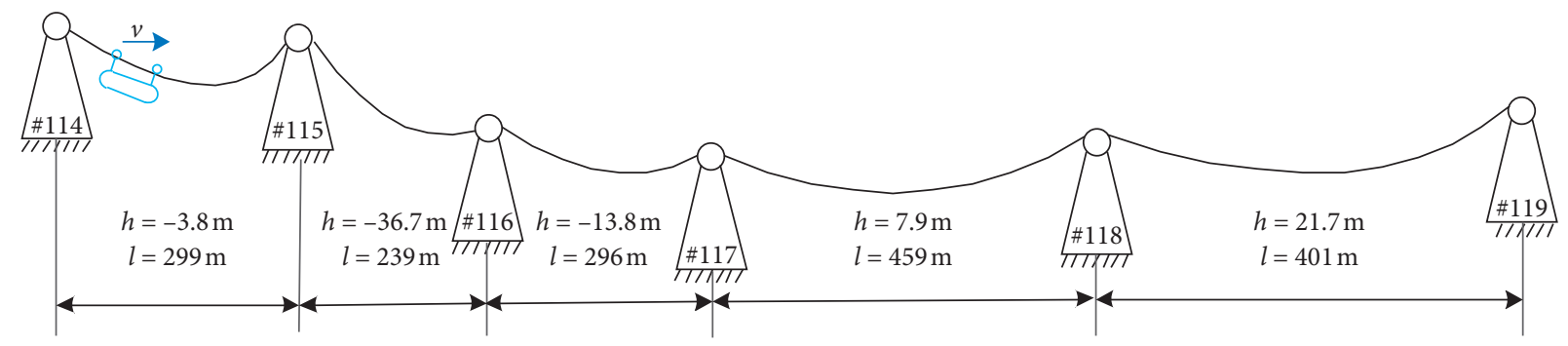

FIGURE 13: Schematic diagram of robot operation in gear \#114-\#119. 


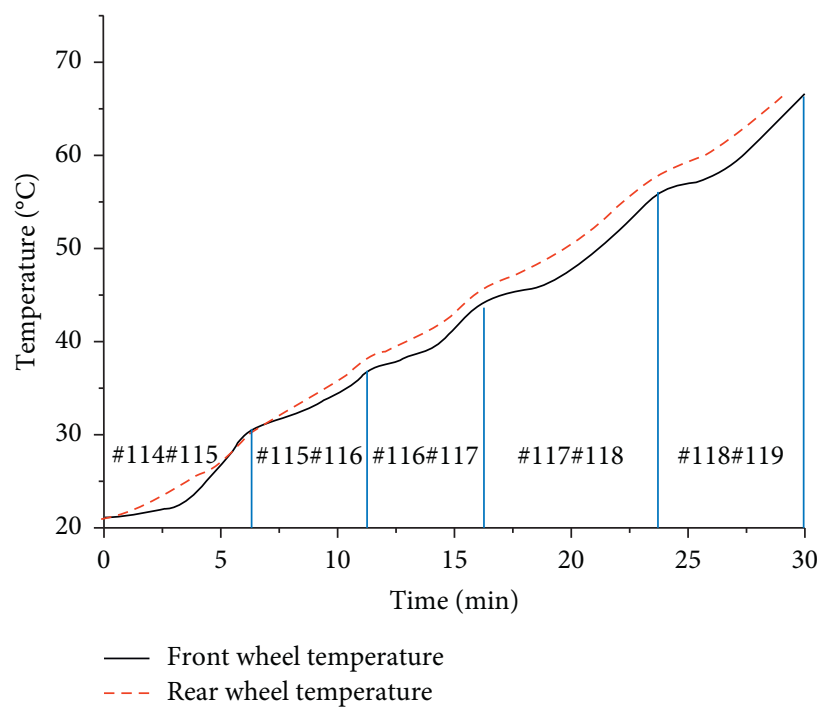

Figure 14: Temperature change curve of traveling wheel in servo drive mode.

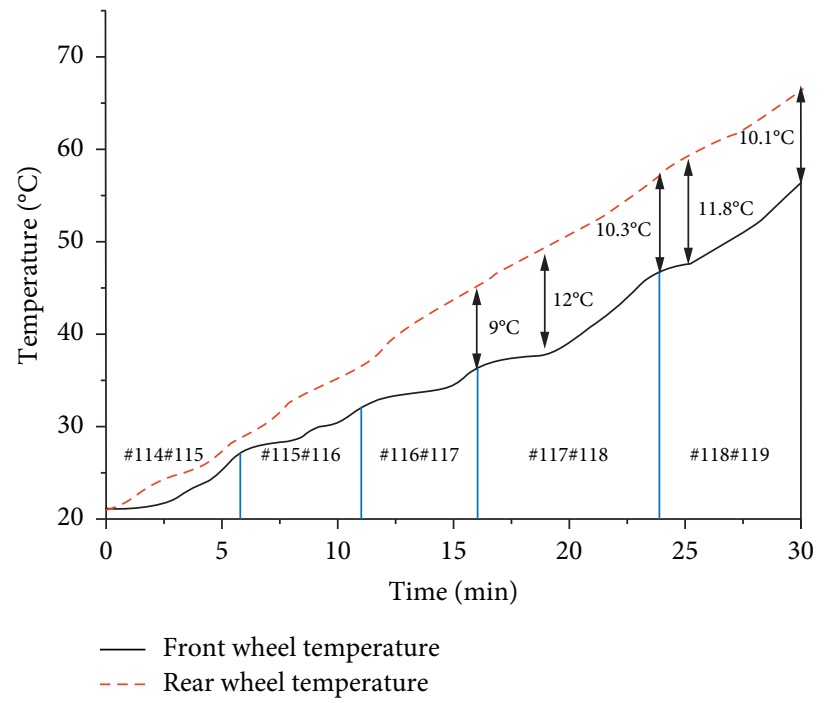

FIGURE 15: Temperature change curve of walking wheel of unpowered downhill model.

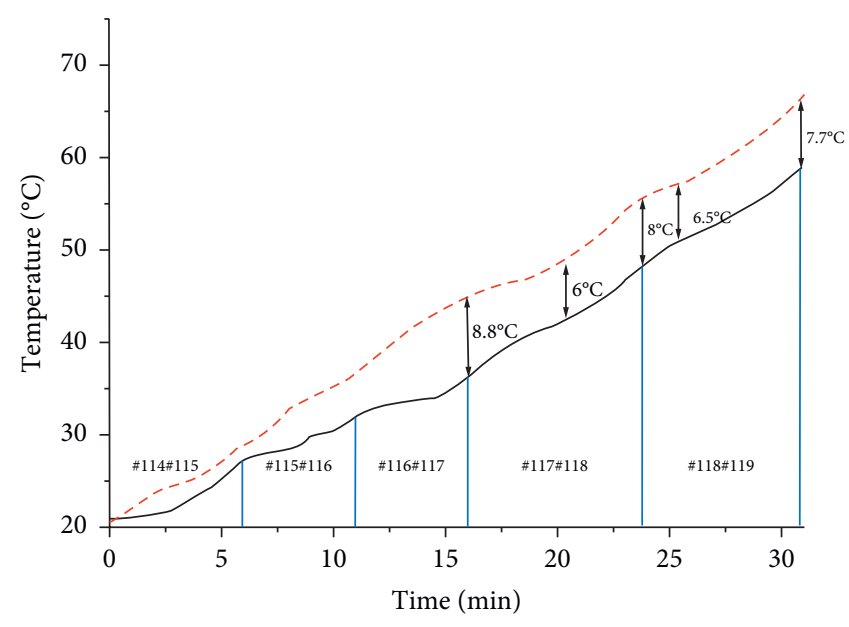

- Front wheel temperature - - Rear wheel temperature

FIgURE 16: Temperature change curve of walking motor after optimization by unpowered downhill strategy. 
on the traveling wheel temperature, which reduces the temperature difference between the front and rear wheel traveling motors.

\section{Conclusion}

With the rapid development of complexity microgrid network lines, the application of high-voltage inspection robots is more and more extensive. This paper puts forward the optimal control strategy based on unpowered downhill speed and energy recovery of inspection robots in complexity microgrid networks for the first time. By adjusting the duty ratio $u$ of the energy consumption speed control system and the distribution factor $\lambda$ of the front wheel feedback brake, the temperature difference between the front and rear wheel traveling motors is reduced, thereby preventing the motor and encoder from being damaged due to the rapid temperature rise of the traveling motor. Through the experimental analysis on the simulated line, it is verified that the unpowered downhill speed and energy recovery optimization control method based on the temperature rise characteristics of the walking motor can effectively reduce the temperature difference between the front and rear wheels, thereby preventing the traveling motor from being damaged by the motor and encoder due to the rapid temperature rise.

\section{Data Availability}

The data used to support the findings of this study are available from the corresponding author upon request.

\section{Conflicts of Interest}

The authors declare that they have no conflicts of interest.

\section{Acknowledgments}

This work was supported by a grant from the National Natural Science Foundation of China (no. 51907055) and Education Department Outstanding Young and Middleaged Science and Technology Innovation Team Project of Hubei Province (no. Q20191404).

\section{References}

[1] J.-W. Jung, V. Q. Leu, T. D. Do, E.-K. Kim, and H. H. Choi, "Adaptive PID speed control design for permanent magnet synchronous motor drives," IEEE Transactions on Power Electronics, vol. 30, no. 2, pp. 900-908, 2015.

[2] J. Liu, H. Li, and Y. Deng, "Torque ripple minimization of PMSM based on robust ILC via adaptive sliding mode control," IEEE Transactions on Power Electronics, vol. 33, no. 4, pp. 3655-3671, 2018.

[3] Y. Xie, X. Tang, B. Song, X. Zhou, and Y. Guo, "Data-driven adaptive fractional order PI control for PMSM servo system with measurement noise and data dropouts," ISA Transactions, vol. 75, pp. 172-188, 2018.

[4] H. Guo, J. Xu, and Y.-H. Chen, "Robust control of faulttolerant permanent-magnet synchronous motor for aerospace application with guaranteed fault switch process," IEEE
Transactions on Industrial Electronics, vol. 62, no. 12, pp. 7309-7321, 2015.

[5] A. D. O. D. S. Dantas, A. F. O. D. A. Dantas, J. T. L. S. Campos, D. L. De Almeida Neto, C. E. T. Dórea, and D. Huang, "PID control for electric vehicles subject to control and speed signal constraints," Journal of Control Science and Engineering, vol. 2018, Article ID 6259049, 11 pages, 2018.

[6] H. Yu, H. R. Karimi, and X. Zhu, "Research of smart car's speed control based on the internal model control," Abstract and Applied Analysis, vol. 2014, Article ID 274293, 5 pages, 2014.

[7] W. T. Asfu, "Stator current-based model reference adaptive control for sensorless speed control of the induction motor," Journal of Control Science and Engineering, vol. 2020, Article ID 8954704, 17 pages, 2020.

[8] K. L. Luna, E. R. Palacios, and A. Marin, "A fuzzy speed controller for a guide robot using an HRI approach," IEEE Latin America Transactions, vol. 16, no. 8, pp. 2102-2107, 2018.

[9] V. Šlapák, K. Kyslan, M. Lacko, V. Fedák, and F. Ďurovský, "Finite control set model predictive speed control of a DC motor," Mathematical Problems in Engineering, vol. 2016, Article ID 9571972, 10 pages, 2016.

[10] H. Jian, W. Gongping, W. Wei, Y. Shoudong, L. Ming, and Y. Zhiyong, "Unpowered downhill speed control method of patrol robot," Journal of Zhejiang University, vol. 49, no. 10, pp. 1878-1884, 2015.

[11] P. Kannan, S. K. Natarajan, and S. S. Dash, "Labview based autonomous agricultural robot using fuzzy logic controller," American Journal of Applied Sciences, vol. 10, no. 11, pp. 1413-1418, 013.

[12] Y. Meng, B. Liu, and L. Wang, "Speed control of PMSM based on an optimized ADRC controller," Mathematical Problems in Engineering, vol. 2019, Article ID 1074702, 18 pages, 2019.

[13] G. Lian, H. Li, B. Chen, F. Ban, and J. Zhang, "Characteristic analysis and temperature rise calculation of PMSM under different power supply modes," IEEE Transactions on Applied Superconductivity, vol. 29, no. 2, pp. 1-5, 2019.

[14] Q. Lu, X. Zhang, Y. Chen, X. Huang, Y. Ye, and Z. Q. Zhu, "Modeling and investigation of thermal characteristics of a water-cooled permanent-magnet linear motor," IEEE Transactions on Industry Applications, vol. 51, no. 3, pp. 2086-2096, 2015.

[15] B. Kim, M. Choi, K. Park, B. Kim, X. Maldague, and T. Takagi, "Analysis of IPMSM characteristics considering the temperature change," International Journal of Applied Electromagnetics and Mechanics, vol. 45, no. 1-4, pp. 315-321, 2014.

[16] Q. Lv, Z. Yao, L. Zhou, and L. Pan, "Effect of temperature rise on characteristics of a standing wave ultrasonic motor," Journal of Intelligent Material Systems and Structures, vol. 30, no. 6, pp. 855-868, 2019.

[17] Y. Xia, Y. Han, Y. Xu, and M. Ai, “Analyzing temperature rise and fluid flow of high-power-density and high-voltage induction motor in the starting process," IEEE ACCESS, vol. 7, pp. 35588-35595, 2019.

[18] Y. Xu, M. Ai, and Y. Yang, "Heat transfer characteristic research based on thermal network method in submersible motor," International Transactions On Electrical Energy Systems, vol. 28, no. 3, Article ID e2507, 2018.

[19] H.-J. An, G.-W. Cho, S.-H. Woo, and G.-T. Kim, “The optimal design of single sided PMLSM for considering winding temperature rising according to thickness of teeth," Journal of Electrical Engineering and Technology, vol. 8, no. 2, pp. 339344, 2013. 
[20] J. Nakatsugawa, Y. Iwaji, and Y. Enomoto, "Extension of mathematical models taking temperature variation in permanent magnet synchronous motors into consideration," Electrical Engineering in Japan, vol. 199, no. 3, pp. 48-56, 2017. 